\title{
Consumer Adoption of Cloud Computing Services in Germany: Investigation of Moderating Effects by Applying an UTAUT Model
}

\author{
Heiko Moryson ${ }^{1} \&$ Guido Moeser ${ }^{2}$ \\ ${ }^{1}$ University of Giessen, Germany \\ ${ }^{2}$ Masem Research Institute, Germany \\ Correspondence: Heiko Moryson, University of Giessen, Faculty of Cultural and Social Sciences, \\ Karl-Glöckner-Str. 21E, 35394 Giessen, Germany. E-mail: heiko.moryson@sowi.uni-giessen.de
}

\author{
Received: January 9, 2016 Accepted: January 20, $2016 \quad$ Online Published: January 28, 2016 \\ doi:10.5539/ijms.v8n1p14 URL: http://dx.doi.org/10.5539/ijms.v8n1p14
}

\begin{abstract}
Cloud computing services have been growing rapidly in recent years, with Dropbox, Apple iCloud and Google Drive being amongst the most established. The main purpose of this study was to investigate whether there were moderator effects for cloud usage. Therefore, Gender, Age, IT Experience, and Usage Context were included as moderating variables. Theoretical backbone was an extension of the Unified Theory of Acceptance and Use of Technology (UTAUT). Herby, we investigated the UTAUT-determinants Performance Expectancy, Effort Expectancy, Facilitating Conditions, and Social Influence plus incorporated external factors Attitude towards Use, Perceived Security Risks and Perceived Trust into the research model.

Data was conducted via a web survey amongst internet users in Germany during October 2014. A total of 2135 panelists started the questionnaire with 2040 finishing. Data basis for the analyses was the number of cloud computing users $(n=1047)$. Operationalization was tested using confirmatory factor analyses and causal hypotheses were evaluated by means of structural equation modeling. In addition, the critical ratios approach was applied to investigate moderating effects.

Firstly, the results show that extended UTAUT is a robust research model. In detail, Social Influence, Performance Expectancy Effort Expectancy, and Perceived Security Risks were shown to significantly impact Attitude towards Use cloud services. The combination of all constructs used accounted for $67.2 \%$ of the variances observed in users' attitude and $82.4 \%$ in users' intention to use cloud services. Secondly, we found the moderating effect for all factors investigated, particularly gender and IT experience were shown to significantly moderate attitude and behavioral intention to use cloud services.
\end{abstract}

Keywords: cloud computing, unified theory of acceptance and use of technology (UTAUT), trust, security risks, structural equation modeling (SEM), critical ratio approach, moderating effects

\section{Introduction}

Cloud Computing is an emerging technology and has already conquered the digital landscape. Based on a definition by Marinescu (2013), the cloud provides the vast amount of storage and computing cycles demanded by many applications. The network-centric content model allows a user to access data from any device connected to the Internet (Marinescu, 2013). We focused on cloud storages, file hosting services that allow users to sync files and later access them from a web browser or mobile device. In fact, the usage of cloud computing storage services like Dropbox, Apple iCloud, Microsoft OneDrive, Amazon Cloud Drive or ownCloud are widely-used in and have become common place in today's private and business related digital environments (Moryson \& Moeser, 2015).

A critical factor for the success of innovations like cloud computing services is to understand the adoption criteria of targeted consumers (Nysveen \& Pedersen, 2014). In a previous study we investigated users' relevant usage determinants when viewed from a technology acceptance perspective (Moryson \& Moeser, 2015). Theoretical frame was an extension of the Unified Theory of Acceptance and Use of Technology (UTAUT). Herby we developed and empirically validated a new research model by extending UTAUT with Perceived Trust and Perceived Security Risk as new factors. Our research addressed the question how the newly included factors influenced the core constructs of UTAUT. 
Cloud based storage services were chosen to be the object of investigation because they well reflected the features of trust and perceived risks and have not been investigated to a great extent. Our sample consists of German cloud users $(n=1047)$. Results of the measurement and structural model test support our proposed research model. The results show that extended UTAUT is a robust research model with strong predictive power. The proportion of explained variance of constructs is substantial with a maximum of $78.8 \%$ for Behavioral Intention to use to cloud services in Germany as a dependent variable (Moryson \& Moeser, 2015).

Although there are several studies applying UTAUT and its extensions in various contexts, research papers with empirical evidence on UTAUT are still limited. Williams et al. (2011) investigated in a meta-analysis several UTAUT studies and demanded as a conclusion a stronger consideration of moderating variables like gender, age, and experience to better understand the sociodemographic influences on acceptance of emerging technology.

We used the occasion, and present here, an empirical study showing the effects of moderating age, gender, IT experience, and usage context to better understand the adoption criteria of German cloud computing users. Theoretical frame is an extension UTAUT developed before (Moryson \& Moeser, 2015). New is the integration of the factor Attitude towards Use corresponding to the theory of planned behavior (Ajzen, 1991) in order to get a more nuanced understanding of the significance of the factors influencing cloud computing usage behavior (Nysveen \& Pedersen, 2014).

Our first contribution to this article is to apply an UTAUT extension (Venkatesh et al., 2003). We extended UTAUT by adding Perceived Trust, Perceived Security Risks and Attitude towards Use cloud computing services. The model allows showing relative influences of ascendants related to technology perceptions and social influences.

A second contribution is the integration of relevant moderating variables like gender, age, and IT experience. Assuming that cloud computing usage is voluntary we excluded the factor voluntariness (Venkatesh et al., 2003) and focus on age, gender and experience as moderating effects. The impact from moderating variables provides detailed information about user segments and how to approach different segments with marketing mix measures. It is therefore an important contribution to the literature on adopting cloud computing services (Nysveen \& Pedersen, 2014).

The paper is organized as follows: In section 2, we will present the model and research questions in detail. Section 3 describes operationalization, sample and hypotheses development. In section 4 data analysis and results will be presented. Section 5 presents concluding remarks and possible applications followed by notes about limitations and future research recommendations.

\section{Research Model and Hypotheses}

Theoretical frame of our research is the Unified Theory of Acceptance and Use of Technology (UTAUT) developed by Venkatesh et al. in 2003. UTAUT is a consolidation of eight prominent theoretical models and was originally validated to facilitate research on information systems (IS)/ information technology (IT) adoption (Williams et al., 2011; Moryson \& Moeser, 2015). UTAUT postulates that four constructs are essential for accepting technology: Performance Expectancy (PE), Effort Expectancy (EE), Facilitating Conditions (FC) and Social Influence (SI). The constructs serve as the direct determinants of behavioral intention, respectively, and, ultimately, behavior (Venkatesh, 2015). Unlike the original theory the impact of Facilitating Conditions (FC) has been measured on behavioral intention (INT) in our model and not on the actual system usage (Moryson \& Moeser, 2015). The specification of the variables can be gathered from the original research (Venkatesh et al., 2003; Moryson \& Moeser, 2015).

In our application UTAUT has been further extended by inclusion of three external constructs. The first two constructs, Perceived Trust and Perceived Security Risks, are both highly relevant factors in the online environment to explain or predict users' acceptance and use of IT (Lee et al., 2010; Moryson \& Moeser, 2015). In our prior study Perceived Trust and Perceived Security Risks were shown to be direct influencers of intention to use cloud services in UTAUT, while trust functions as both a direct and indirect influencer through Perceived Security Risks, Performance Expectancy, and Effort Expectancy. Additionally, Social Influence, Facilitating Conditions, Performance Expectancy and Effort Expectancy were shown to positively affect Behavioral Intention. Effort Expectancy was shown to significantly influence Performance Expectancy (Moryson \& Moeser, 2015).

Another key result was that the combination of Perceived Trust, Perceived Security Risks, Performance Expectancy, Effort Expectancy, Facilitating Conditions and Social Influence accounted for $78.8 \%$ of the variances observed in users' intention to use cloud services in Germany (Moryson \& Moeser, 2015). It was 
higher than in the original UTAUT (without considering trust and security risks) in Venkatesh et al. (2003) with $69 \%$ of intention to use. It indicates that extended UTAUT with Perceived Trust and Perceived Security Risks included has strong predictive power (Moryson \& Moeser, 2015).

The third new construct to be integrated is Attitude towards Use (AtU) cloud computing services. It is defined as "the individual's positive or negative feelings about performing a behavior "(Ajzen, 1991). This is in "one step back in comparison to the UTAUT model" (Nysveen \& Pedersen, 2014). However, actual research findings show that general attitudinal measures of technology are highly significant antecedents of intention to use (Nysveen \& Pedersen, 2014; Müller-Seitz et al., 2009; Pramatari \& Theotokis, 2009; Boslau \& Lietke, 2006). Furthermore, Attitude is a fix component of the initial Technology Acceptance Model (TAM by Davis et al., 1989) and other TAM related studies (e.g., Moeser et. al., 2013) underscoring the importance of the attitudinal determinant. Consequently, it was decided to adapt the research model and substitute the variables Intention to Use with Attitude towards Use and Actual Usage with Intention to Use in order to align the model with the current empirical findings and to better understand the moderating effects with respect to different user segments. Coinciding with the Theory of Planned Behavior (Ajzen, 1991), we set a causal chain from Attitude to Use, Intention to Use and finally Actual Usage of an object. Herby our focus is still on on usage constructs like Attitude towards Use and Intention to Use and not objects constructs meaning attitude to object (Nysveen \& Pedersen, 2014). Based on the discussions by Moore \& Bernbasat (1991), the key to success of an innovation is not the perception of this innovation, but the perception of using the innovation (Nysveen \& Pedersen, 2014). So, by keeping the focus on the usage perceptions we believe this is a reasonable approach to adapt the UTUAT model (Nysveen \& Pedersen, 2014). Our main goal in this study is to better understand the motives for the usage with respect to user segments with a focus on the moderating effects rather than to explain the highest variances observed in the intention to use cloud computing services as we did in our previous study (Moryson \& Moeser, 2015). After all constructs are presented, the final research model is depicted graphically in Figure 1.

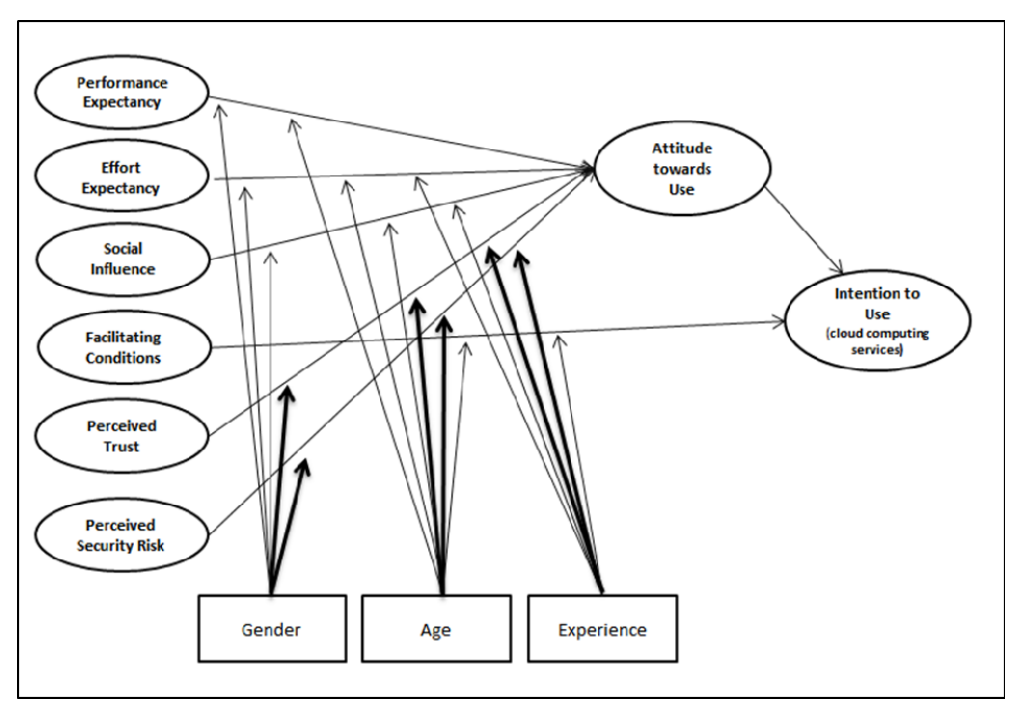

Figure 1. Final research model, an extension of the unified theory of acceptance and use of technology (UTAUT) Note. bold arrows in represent extensions from the original UTAUT.

In the model we let attitude to use and intention to use substitute intention to use and actual usage from the original UTAUT (Nysveen \& Pedersen, 2014; Venkatesh et al., 2003). Facilitating conditions and attitude to use are proposed to influence intention to use, mirroring the influences of facilitating conditions and intention to use on actual usage from the original UTAUT model (Nysveen \& Pedersen, 2014; Venkatesh et al., 2003). Finally, Perceived Trust and Perceived Security Risks are added to the original UTAUT as antecedents of Attitude towards Use cloud computing services in Germany. As moderating variables Venkatesh et al. (2003) proposed Gender, Age, Experience and whether the usage is mandatory or voluntary. We substituted the voluntariness variable with Usage Context as moderating variable as we assume a voluntary usage and are interested to see if there are any differences amonst private and business cloud users. 


\subsection{Research Questions}

If our approach was to be summarized in a single question, it would be: "What are the psychological mechanisms associated with cloud computing usage for each user segment, when seen from a technology acceptance perspective?"

Of course, such a question needs some decomposition in order to be tested systematically and empirically. In particular, we focused on examining several research questions of different granularity, which arose before the background of the UTAUT model. The first and most obvious question is whether the extended UTAUT is an appropriate approach to explain cloud computing usage adoption? Given that UTAUT as a generalized model can be considered as appropriate, the next question relates to the pattern of moderating effects. Where are the biggest differences between the user groups? And what are the strongest influences and what are the orders of magnitude of the effects? And finally of course, how do the newcomers Attitude towards Use, Perceived Trust, and Perceived Security Risks influence the core UTAUT constructs? Given the case of cloud computing, we expect the influence of Performance Expectancy and Social Influence to be substantive. However, the roles of the moderating variables in combination with the UTAUT core constructs and the three novices and are not clear at this point and will be subject to closer examination.

\subsection{Hypotheses \\ a. Core Variables}

Based on the results of the original research of Venkatesh et al. $(2003 ; 2012)$ and the connected studies (Moryson \& Moeser, 2015; Nysveen \& Pedersen, 2014; Lee et al., 2010; Pavlou, 2003; Gefen et al., 2003; Gefen, 2000; Pavlou \& Gefen, 2004; Nicolaou \& McKnight, 2006; Williams et al., 2011; Lee, 2009; Crespo et al., 2009; Esteva-Armida \& Rubio-Sanchez, 2014; Guo \& Barnes, 2007; Cody-Allen \& Kishore, 2006) plus assuming a direct link between Attitude to Use and Behavioral Intention to use (Ajzen, 1991), we set up the following hypotheses:

H1: Performance Expectancy (PE) will have a positive influence on Attitude to Use (AtU) cloud computing services in Germany.

H2: Effort Expectancy (EE) will have a positive influence on Attitude to Use (AtU) cloud computing services in Germany.

H3: Social Influence (SI) will have a positive influence on Attitude to Use (AtU) to use cloud computing services in Germany.

H4: Facilitating Conditions (FC) will have a positive influence on the Behavioral Intention (INT) to use cloud computing services in Germany.

H5: Perceived Trust (TR) will have a positive effect on Attitude to Use (AtU) cloud computing services in Germany.

H6: Perceived Security Risk (PSR) will have a negative effect on Attitude to Use (AtU) cloud computing services in Germany.

H7: Attitude to Use (AtU) will have a positive effect on Behavioral Intention (INT) to use cloud computing services in Germany.

\section{b. Moderating Variables}

\section{1) Gender}

UTAUT model suggests that in general men are relatively more task-oriented than women (Venkatesh et al., 2003; Minton \& Schneider, 1985; Nysveen \& Pedersen, 2014). Subsequently, the authors propose that the effect of Performance Expectancy is stronger for men than for women. However, the results from Venkatesh et al. (2012) to explain consumers' adoption of mobile Internet did not show any moderating effects of gender on the influence of performance expectancy on behavioral intention (Nysveen \& Pedersen, 2014). Adapted to our model, we propose the following hypothesis:

H8a: Performance Expectancy (PE) will influence Attitude to Use (AtU) cloud computing services in Germany more strongly for men than for women.

Original UTAUT proposes that Effort Expectancy is more significant among women than among men (Venkatesh et al., 2003). Again, no empirical evidence for this hypothesis was found in the connected study on consumers' adoption of mobile internet (Venkatesh et al., 2012). Adapted to our research model, we nominate the following hypothesis: 
H8b: Effort Expectancy (EE) will influence Attitude to Use (AtU) cloud computing services in Germany more strongly for women than for men.

Social Influence is as well proposed as more significant for women than for men in UTAUT (Venkatesh et al. 2003) and another study (Nysveen \& Pedersen, 2014). However, no empirical evidence was found that gender moderates the effect of Social Influence on intention to use neither in the original research on a general basis (Venkatesh et al., 2003) nor in the study on consumers' adoption of mobile internet (Venkatesh et al., 2012; Nysveen \& Pedersen, 2014). However, adapted to our research model, we propose:

H8c: Social Influence (SI) will influence Attitude to Use (AtU) cloud computing services in Germany more strongly for women than for men.

Awad \& Ragowsky (2014) showed that the effect of Perceived Trust on intention to shop online is stronger for women than for men. Based on these findings we propose that trust will be a more salient factor for the adoption of cloud computing services in Germany among women than among men.

H8d: Perceived Trust (TR) will influence Attitude to Use (AtU) cloud computing services in Germany more strongly for women than for men.

We found several studies reporting that women are more worried about data privacy issues in the online context than men (Nysveen \& Pedersen, 2014; Garbarino \& Strahilevitz, 2004; Alston et al., 2006; Ronan \& Kim, 2006). Therefore, we propose:

H8e: Perceived Security Risks (PSR) will influence Attitude to Use (AtU) cloud computing services in Germany more strongly for women than for men.

\section{2) Age}

Generally, the studies considering age as moderating variable are limited. Venkatesh et al. (2003) propose in the original UTAUT research that Performance Expectancy has a stronger influence on intention to use technology among younger users than among older users (Nysveen \& Pedersen, 2014). Venkatesh's hypothesis is based on theoretical thoughts of Hall \& Mansfield (1975) and Porter (1963) who suggest that extrinsic rewards are more important for younger compared to older people (Nysveen \& Pedersen, 2014). However, Venkatesh did not find empirical support for this hypothesis neither in study on a general basis (Venkatesh et al., 2003) nor in the study on consumers' adoption of mobile internet (Venkatesh et al., 2012). However, adapted to our research model, we propose:

H9a: Performance Expectancy (PE) will influence Attitude to Use (AtU) cloud computing services in Germany more strongly for younger people than for older people.

For Effort Expectancy the UTAUT research model propose a moderating effect by age (Venkatesh et al., 2003). Their assumption, the effect on Effort Expectancy will be stronger amongst older users than amongst younger users, is based on Plude \& Hoyer (1985). They argue that older persons have relatively more issues handling complex stimuli. However, the UTAUT authors did not find empirical support for this hypothesis neither in their study on a general basis (Venkatesh et al., 2003) nor in the study on consumers' adoption of mobile internet (Venkatesh et al., 2012; Nysveen \& Pedersen, 2014). Corresponding to our proposed research model, we set up the following hypothesis:

H9b: Effort Expectancy (EE) will influence Attitude to Use (AtU) cloud computing services in Germany more strongly for older people than for younger people.

UTAUT model also proposes that age moderates the effect of Social Influence on Intention to use (Venkatesh et al., 2003). Accordingly, Social Influence will be more significant among younger people than among older people. The assumption is originally based on a study of Rhodes (1983) with the argument that older people have a stronger need for affiliation (Nysveen \& Pedersen, 2014). However, the empirical results of Venkatesh et al. (2003; 2012) did not find any support for this hypothesis. As we follow our described research model, we nominate the following hypothesis:

H9c: Social Influence (SI) will influence Attitude to Use (AtU) cloud computing services in Germany more strongly for older people than for younger people.

Venkatesh et al. (2003) also propose that age moderates the effect of Facilitating Conditions on actual usage (Nysveen \& Pedersen, 2014). The assumption is based on Hall \& Mansfield (1975) who argue that older people are more willing to seek support and help in the job than younger people (Nysveen \& Pedersen, 2014). Venkatesh et al. (2003) found strong support for their hypothesis conducted in an organizational context while no empirical evidence was found in the study on consumers' adoption of mobile internet (Venkatesh et al., 2012; 
Nysveen \& Pedersen, 2014). Based on the findings of the original research and corresponding to our model, we set up the following hypothesis:

H9d: Facilitating Conditions (FC) will influence Attitude to Use (AtU) cloud computing services in Germany more strongly for older people than for younger people.

Perceived Trust is proposed to positively influence Attitude towards Use (AtU). Although there are many studies investigating the influence of trust in the online environment, we found a lack of studies considering moderating effects in this context. Our assumption is that older users are more sensitized for possible issues with trust in data privacy protection, and hence we propose:

H9e: Perceived Trust (TR) will influence Attitude towards Use (AtU) cloud computing services in Germany more strongly for older people than for younger people.

Perceived Security Risks is proposed to negatively influence Attitude towards Use (AtU). Our assumption is that the level of perceived security risks goes in line with an increasing age. However, we did find no empirical support. Based on our research model, we propose the following hypothesis:

H9f: Perceived Security Risks (PSR) will influence Attitude to Use (AtU) cloud computing services in Germany more strongly for older people than for younger people.

\section{3) Experience}

In general, studies considering experience moderating UTAUT variables are limited. Our experience factor is based on the variable IT experience in years.

It is supposed that Effort Expectancy is perceived as an essential factor for adoption when users are unexperienced with the technology and the technology represents difficult hurdles for potential users (Venkatesh et al., 2003; Nysveen \& Pedersen, 2014). While such concerns are fundamental at low levels of experience, the effect is supposed to gradually be reduced as experience with the technology increases (Nysveen \& Pedersen, 2014). However, no empirical support is shown for this hypothesis in UTAUT (Venkatesh et al., 2003; 2012; Nysveen \& Pedersen, 2014). However, our proposed theory model implies that:

H10a: Effort Expectancy (EE) will influence Attitude to Use (AtU) cloud computing services in Germany more strongly for people with a low level of IT experience than for people with a high level of IT experience.

Social Influence is also reported to be moderated by experience, influencing intention to use in UTAUT (Venkatesh et al., 2003). While users often listen to important persons like friends and family when they have a low level of experience, with an increasing level of experience they are more willing to make decisions about adoption on their own perception (Venkatesh et al., 2003; Nysveen \& Pedersen, 2014). However, none of the studies by Venkatesh found empirical evidence that experience moderates the effect of Social Influence on intention to use (Venkatesh et al., 2003; Venkatesh et al., 2012; Nysveen \& Pedersen, 2014). However, based on our theoretical assumptions we nominate the hypothesis:

H10b: Social Influence (SI) will influence Attitude to Use (AtU) cloud computing services in Germany more strongly for people with a low level of IT experience than for people with a high level of IT experience.

Facilitating Conditions are proposed to positively influence actual usage behavior (Venkatesh et al., 2003). Based on the UTAUT study the effect becomes stronger as the level of experiences with the technology increases (Venkatesh et al., 2003; Nysveen \& Pedersen, 2014). The reason for this may be, according to Bergeron et al. (1990), that more experienced users have a better understanding of how to ask for support and help (Nysveen \& Pedersen, 2014). Although no empirical evidence was found in Venkatesh's both studies (Venkatesh et al., 2003; 2012), we propose the following hypothesis due to our theoretical assumptions:

H10c: Facilitating Conditions (FC) will influence Intention to Use (INT) cloud computing services in Germany more strongly for people with a high level of IT experience than for people with a low level of IT experience.

Perceived Trust is proposed to positively influence Attitude towards Use. Again, we found a lack of studies considering moderating effects in this context. Our assumption is that users with a high level of experience are more sensitized for possible issues with trust in data privacy protection, and hence we propose:

H10d: Perceived Trust (TR) will influence Attitude to Use (AtU) cloud computing services in Germany more strongly for people with a high level of IT experience than for people with a low level of IT experience.

Perceived Security Risks are proposed to negatively influence attitude towards cloud usage. In general, there is a lack of empirical findings considering moderating effects in this context. Our assumption is that the level of perceived security risks goes in line with an increasing level of experience. Im et al. (2008) found marginal 
moderating effects of user experience. Based on their findings and following our proposed research model we nominate the hypothesis:

H10e: Perceived Security Risks (PSR) will influence Attitude to Use (AtU) cloud computing services in Germany more strongly for people with a low level of IT experience than for people with a high level of IT experience.

\section{4) Usage Context}

The variable is based on the question "if respondents use cloud services in a private or in a business context?" Studies considering usage context as a moderating variable in combination with UTAUT were not found. As it is neither hypothesized in original UTAUT nor found in any related studies, we do not put it into the core model but present results for investigated moderating effects in section 4 .

\section{Method \& Data}

An empirical study was designed to investigate the influences of the proposed antecedents on adoption of cloud computing services in Germany. The study was organized as an online survey, and data were collected during a period of 10 days in the beginning of October, 2014. The questionnaire, stimulus material, and survey procedure were developed by the authors, while Survey Sampling International (SSI), a professional panel provider, was responsible for collecting the data.

Before formulating the questionnaire items, we followed recommendations by Fishbein \& Ajzen (2010) and conducted qualitative interviews with five persons to gather deeper insight into the behavior and its relevant determinants.

After analyzing the collected qualitative interviews, questions had been formulated in concordance to recommendations of Davis et al. (1989) and Fishbein \& Ajzen (2010). Measurement items and scales were modified to operationalize the constructs from the original measures provided by Venkatesh et al. (2003) and Gefen (2000). All constructs have been operationalized using multi-item scales to avoid problems regarding reliability (Ajzen 2005). After formulation of the first draft of the questionnaire, cognitive pretests had been conducted. This resulted in shortening the quite long questionnaire and a reformulation of selected items.

Respondents were asked to evaluate on a 7-point Likert scale in the questionnaire. The final version was programmed in the online questionnaire tool SoSci Survey $(\mathrm{oFb})$ and tested again. Some items have been excluded after the pretests and a small amount has been excluded after data collection and conducting some descriptive analyses. All items were formulated in German, so we will only present English translations of the final items here, which can be found in Table 3.

Data was conducted via a web survey of internet users in Germany in October 2014. The questionnaire was developed, implemented and hosted on scientific platform SoSci Survey $(\mathrm{oFb})$. A total of 2135 respondents started the questionnaire with 2040 (95.7\%) finishing the questions. Data basis for the analyses here is the number of cloud computing users $(\mathrm{n}=1047)$.

The most used platform of our survey respondents was Dropbox (usage rate 79.38\%) followed by Google Drive (62.42\%), Apple iCloud (52.91\%), Microsoft OneDrive (45.61\%), Amazon Cloud Drive (44.61\%), and ownCloud $(23.66 \%)$ - multiple answers were possible indicating that several respondents use more than one cloud platform. Table 1 summarizes the usage statistics of the top 6 selected cloud service platforms.

Table 1. Number of users vs. number of no-user of the survey respondents (multiple answers possible)

\begin{tabular}{lll}
\hline & Number of users & no users \\
\hline Dropbox & 774 & 201 \\
Google Drive & 583 & 382 \\
Apple iCloud & 519 & 462 \\
Microsoft OneDrive (former SkyDrive) & 426 & 508 \\
Amazon Cloud Drive & 418 & 519 \\
ownCloud (open source) & 217 & 705 \\
\hline
\end{tabular}

Our sample can be considered as heterogeneous. Fifty-one percent of the respondents were female, and forty-nine percent were male. Age groups are distributed equally.

Average age of the respondents is 37.21 years at MEAN (SD 12.2; MEDIAN 36). The youngest respondent is 14 years old, the oldest 64 years of age. The education level is also well distributed and ranges from no completed 
education level $(9.7 \%)$ to university degree $(18.4 \%)$, whereby the education levels in between are also well represented in our sample. Our respondents are quite experienced with information technology (IT) as the peak answered "more than 10 years" of IT experience.

It is not possible to compare the empirical distribution of our sample with official data as the cloud providers do not publish any data. What we can say is that $80 \%$ of the general population in Germany has access to the internet. Our sample gross lies in the age groups 14-50 years where the vast majority has access to the internet: age groups 10-15 years: 97\%; 16-24 years: 99\%; 25-44 years: 98\%; 45-64 years: 85\% (Statistisches Bundesamt, Wiesbaden 2014). The vast majority has used the internet during the last three months and $72 \%$ are using the Internet for banking services (Statistisches Bundesamt, Wiesbaden 2014). Consequently, we believe the online panel data is reasonable representative for the general population in Germany aged 14 years and older.

We can also provide a rough estimation of the cloud users' data when having a look at data from web information supplier Alexa Internet that provides web traffic data. When having a look at these data of the respective cloud services it can be considered that our own data only slightly differs in the distribution of gender and education level. The empirical distribution of gender is very equal to the data provided by Alexa, but shows a slightly lesser proportion of women than our sample represented. The education level is slightly higher in the Alexa data as well, as the majority of users have, in contrary to our sample, a college degree. The distribution of ages and IT experience does not deviate from those communicated by Alexa Internet. Table 2 summarizes the sample demographics. Taken together, our sample shows, if any, only small deviations from what can be considered the entire population's distribution. However, we can see no evidence for a systematic sampling error or self-selection bias (Moryson \& Moeser, 2015).

Table 2. Demographics of the survey respondents

\begin{tabular}{llll}
\hline Measure & Frequency & Percent & Valid N \\
\hline Gender & & & 1004 \\
Female & 490 & 51.2 & \\
Male & 514 & 48.8 & 998 \\
Age (in years) & & & \\
$14-20$ & 70 & 7 & \\
$21-30$ & 284 & 28.4 & \\
$31-40$ & 246 & 24.6 & \\
$41-50$ & 229 & 22.9 & \\
$51-60$ & 144 & 14.5 & \\
$61+$ & 25 & 2.6 & \\
Highest education level & & & \\
No completed education level & 95 & 9.7 & \\
Apprenticeship or comparable & 323 & 32.7 & \\
Technical school education or comparable & 166 & 16.7 & \\
College of higher education or comparable & 224 & 22.5 & \\
University & 183 & 18.4 & \\
IT experience (in years) & & & \\
$0-1$ & 74 & 7.3 & \\
$1-2$ & 143 & 14.2 & \\
$3-5$ & 179 & 17.8 & \\
$6-10$ & 196 & 19.4 & \\
More than 10 years & 416 & 41.3 & \\
& & & \\
\hline
\end{tabular}

An overview of means, medians, standard deviations, skewness, percentage of missing values per item and the demographic variables is given in Table 3. 
Table 3. Overview of items and demographic variables

\begin{tabular}{|c|c|c|c|c|c|c|c|}
\hline & & $\begin{array}{l}\text { Valid } \\
\text { cases }\end{array}$ & Missing \% & Mean & Median & $\begin{array}{l}\text { Std. } \\
\text { Dev. }\end{array}$ & Skewness \\
\hline \multicolumn{8}{|c|}{ Sociodemographics } \\
\hline SD_1 & Respondent's exact age & 998 & 4.4 & 37.2 & 36 & 12.2 & 0.2 \\
\hline SD_2 & $\begin{array}{l}\text { The highest level of educatioin - } \\
\text { respondent }\end{array}$ & 1008 & 3.7 & 3.1 & 3 & 1.3 & 0.1 \\
\hline SD_3 & Respondent's exact IT experience & 1008 & 3.7 & 3.7 & 4 & 1.3 & -0.6 \\
\hline \multicolumn{8}{|c|}{ Performance Expectancy (PE) } \\
\hline PE_1 & $\begin{array}{l}\text { Using cloud services helps me } \\
\text { accomplish my tasks more efficient. }\end{array}$ & 975 & 6.8 & 4.8 & 5 & 1.6 & -0.5 \\
\hline PE_2 & $\begin{array}{l}\text { Using cloud services allows me a } \\
\text { faster data management. }\end{array}$ & 981 & 6.7 & 5.0 & 5 & 1.6 & -0.6 \\
\hline \multicolumn{8}{|c|}{ Effort Expectancy (EE) } \\
\hline EE_1 & I find cloud services easy to use. & 1011 & 3.4 & 5.5 & 6 & 1.3 & -0.7 \\
\hline EE_2 & $\begin{array}{l}\text { Learning how to use cloud services is } \\
\text { easy for me. }\end{array}$ & 985 & 5.9 & 5.4 & 6 & 1.4 & -0.7 \\
\hline \multicolumn{8}{|c|}{ Facilitating Conditions (FC) } \\
\hline FC_1 & $\begin{array}{l}\text { I have the technical resources } \\
\text { necessary to use cloud services. }\end{array}$ & 1010 & 3.5 & 6.0 & 6 & 1.2 & -0.8 \\
\hline FC_2 & $\begin{array}{l}\text { Cloud services are compatible with } \\
\text { other applications I use. }\end{array}$ & 963 & 8.4 & 5.4 & 6 & 1.4 & -0.7 \\
\hline \multicolumn{8}{|c|}{ Social Influence (SI) } \\
\hline SI_1 & $\begin{array}{l}\text { People who are important to me think } \\
\text { that I should use cloud services. }\end{array}$ & 844 & 19.4 & 4.4 & 5 & 1.7 & -0.4 \\
\hline SI_2 & $\begin{array}{l}\text { Overall, my social circle supports the } \\
\text { usage of cloud services. }\end{array}$ & 874 & 16.5 & 4.8 & 5 & 1.6 & -0.6 \\
\hline \multicolumn{8}{|c|}{ Attitude to Use (AtU) semantic differential (7-point) } \\
\hline AtU_1 & $\begin{array}{l}\text { Using cloud services is a bad idea/a } \\
\text { good idea. }\end{array}$ & 1018 & 3.2 & 5.9 & 6 & 1.2 & -1.2 \\
\hline AtU_2 & $\begin{array}{l}\text { Using cloud services is } \\
\text { disadvantageous/advantageous. }\end{array}$ & 1008 & 3.7 & 5.6 & 6 & 1.3 & -0.9 \\
\hline \multicolumn{8}{|c|}{ Perceived Security Risks (PSR) } \\
\hline PSR_1 & $\begin{array}{l}\text { When using cloud services my data } \\
\text { can be lost. }\end{array}$ & 929 & 11.3 & 3.6 & 5 & 1.7 & -0.5 \\
\hline PSR_2 & $\begin{array}{l}\text { Using cloud services is at risk for my } \\
\text { privacy. }\end{array}$ & 949 & 9.4 & 3.8 & 4 & 1.7 & 0.2 \\
\hline \multicolumn{8}{|c|}{ Perceived Trust (TR) } \\
\hline TR_1 & $\begin{array}{l}\text { I have trust in the protection of data } \\
\text { privacy of cloud services. }\end{array}$ & 990 & 5.4 & 4.4 & 5 & 1.7 & -0.4 \\
\hline TR_2 & $\begin{array}{l}\text { I think the suppliers of cloud services } \\
\text { are trustworthy. }\end{array}$ & 981 & 6.3 & 4.7 & 5 & 1.5 & -0.5 \\
\hline \multicolumn{8}{|c|}{ Behaviorial Intention (INT) } \\
\hline INT_1 & $\begin{array}{l}\text { I plan to further use cloud services in } \\
\text { the next four weeks. }\end{array}$ & 967 & 7.6 & 5.3 & 6 & 1.8 & -0.9 \\
\hline INT_2 & $\begin{array}{l}\text { I intend to continue cloud services in } \\
\text { the near future. }\end{array}$ & 980 & 6.4 & 5.4 & 6 & 1.5 & -0.9 \\
\hline
\end{tabular}

\section{Analysis \& Results}

Empirical results are presented in an analysis of both the measurement model and structural equation model for investigating direct effects. For indirect effects moderating variables were investigated applying group comparisons.

\subsection{Data Analysis Method}

Before starting with the actual data analyses, a setup of several tests had been performed in order to ensure the reliability and discriminant validity of the instruments. Analysis of sample composition was performed with SPSS in version 18.0. Confirmatory factor analysis (CFA) was used to examine the convergent validity of each multi-item scale, through specifying a separate single factor model for each construct. After testing every single factor, all factor models were included simultaneously in a final model in order to investigate joint reliability and 
validity of measurement items. The research model was tested using structural equation modeling (SEM) techniques applying Mplus software in version 6.1. SEM is a complete approach to testing hypothesizes about relationships among observed and latent variables. It is highly recommended in our case permitting simultaneous estimation of both measurement and structural models (Bollen, 1989). Moderating variables were used to investigate indirect effects applying critical ratios approach (Byrne, 2010) using group comparisons in AMOS 22.

\subsection{Analysis of the UTAUT Measurement Model}

Confirmatory factor analysis (CFA) was performed to check the fit of the measurement model.

We started with the measurement setup of the extended version of the Unified Theory of Acceptance and Use of Technology (UTAUT) developed by Venkatesh et al. (2003). As an estimator, we used recommended weighted least squares means and adjusted variance (WLSMV). WLSMV is a robust estimator that provides the best option for modelling categorical data (Brown, 2006). Standardized factor loadings are depicted in Table 4.

Table 4. Factor loadings, standard errors, significance and SMC of all constructs included in the extended UTAUT.

\begin{tabular}{|c|c|c|c|c|}
\hline Item & Factor Loadings & S.E. & Two-Tailed P-Value & SMC \\
\hline \multicolumn{5}{|c|}{ Performance Expectancy (PE) } \\
\hline PE_1 & 0.825 & 0.015 & 0.000 & 0.681 \\
\hline PE_2 & 0.799 & 0.015 & 0.000 & 0.638 \\
\hline \multicolumn{5}{|l|}{ Effort Expectancy (EE) } \\
\hline EE_1 & 0.767 & 0.02 & 0.000 & 0.588 \\
\hline EE_2 & 0.836 & 0.019 & 0.000 & 0.699 \\
\hline \multicolumn{5}{|c|}{ Facilitating Conditions (FC) } \\
\hline FC_1 & 0.633 & 0.025 & 0.000 & 0.401 \\
\hline FC_2 2 & 0.702 & 0.025 & 0.000 & 0.493 \\
\hline \multicolumn{5}{|l|}{ Social Influence (SI) } \\
\hline SN_1 & 0.795 & 0.016 & 0.000 & 0.632 \\
\hline SN_2 & 0.809 & 0.016 & 0.000 & 0.654 \\
\hline \multicolumn{5}{|c|}{ Perceived Security Risks (PSR) } \\
\hline PSR_1 & 0.64 & 0.037 & 0.000 & 0.410 \\
\hline PSR_2 & 0.882 & 0.043 & 0.000 & 0.778 \\
\hline \multicolumn{5}{|l|}{ Perceived Trust (TR) } \\
\hline TR_1 & 0.911 & 0.012 & 0.000 & 0.830 \\
\hline TR_2 & 0.907 & 0.012 & 0.000 & 0.823 \\
\hline \multicolumn{5}{|c|}{ Attitude towards Use (AtU) } \\
\hline AtU_1 & 0.807 & 0.018 & 0.000 & 0.651 \\
\hline AtU_2 & 0.783 & 0.018 & 0.000 & 0.613 \\
\hline \multicolumn{5}{|c|}{ Behavorial Intention (INT) } \\
\hline INT_1 & 0.736 & 0.018 & 0.000 & 0.542 \\
\hline INT_2 & 0.926 & 0.013 & 0.000 & 0.857 \\
\hline
\end{tabular}

The following recommended model-fit measures were used to evaluate the measurement model's overall fit (Hu \& Bentler 1999; Brown 2006): Comparative Fit Index (CFI); Tucker-Lewis-Index (TLI), Root Mean Square Error of Approximation (RMSEA) and p-value. CFI and TLI are some of the most robust model and recommended fit indices (Hu \& Bentler, 1999). RMSEA is also an important aspect to be considered. It defines the divergence between the offered model and the population covariance matrix (Hair, 2014b). Model-fit indices observed and recommended values are listed in Table 5.

Table 5. Overall model fit indices for the UTAUT measurement model

\begin{tabular}{|c|c|c|}
\hline Model-Fit Indices & Measurement Model & Recommended Values \\
\hline CFI & 0.974 & $>=0.9$ \\
\hline TLI & 0.956 & $>=0.9$ \\
\hline RMSEA & 0.044 & $<=0.10$ \\
\hline \multicolumn{3}{|c|}{ Estimator: Weighted least squares means and variance adjusted (WLSMV) } \\
\hline Degrees of freedom (df): 102 & $\mathrm{Chi}^{2}\left(\chi_{\text {Min })}=310.009\right.$ & p-value $=0.0000$ \\
\hline
\end{tabular}


Chi-square value is min. 310.009 at 102 degrees of freedom. The chi-square statistic was found to be significant ( $p$-value $=0.000)$, indicating a misfit between model and data. However, it should be noted that the chi-square statistic is assumed to be generally very sensitive to sample size and model complexity. If it is medium or large, as in our case where $\mathrm{n}$ equals 1039 and the number of observed items equals 16, the statistic tends to be significant even though differences between the data generated and the proposed model was low (Hair, 2014a). Taking this into consideration the model fit can be considered as acceptable. All other indicators surpassed the recommended levels (Hu \& Bentler, 1999) which indicates that the operationalization was statistically appropriate.

Overall, all indices demonstrated an adequate fit for the measurement model and achieved the recommended values. Therefore we proceeded with the structural equation modeling.

\subsection{Structural Equation Modeling}

Our research model has been tested in a path model in order to answer our list of research questions. All indicators surpassed the recommended levels (Hu \& Bentler, 1999) which provided evidence of a good model-fit as can be seen from Table 6 .

Table 6. Overall model fit indices for the extended UTAUT structural model

\begin{tabular}{|c|c|c|}
\hline Model-Fit Indices & Measurement Model & Recommended Values \\
\hline CFI & 0.979 & $>=0.9$ \\
\hline TLI & 0.970 & $>=0.9$ \\
\hline RMSEA & 0.077 & $<=0.10$ \\
\hline \multicolumn{3}{|c|}{ Estimator: Weighted least squares means and variance adjusted (WLSMV) } \\
\hline Degrees of freedom (df): 69 & $\underline{\mathrm{Chi}^{2}}\left(\chi_{\text {Min }}\right)=582.577$ & p-value $=0.0000$ \\
\hline
\end{tabular}

Chi-square value is min. 582.577 at 82 degrees of freedom. Again, extended UTAUT shows a significant misfit between model and observations ( $\mathrm{p}$ value $=0.000$ ), while its non-inferential fit-measures are looking fine. As in the case of the test of operationalization, we conclude that this significant chi-square statistic is due to our relatively big sample size and model complexity. All together the model is found to be acceptable.

\subsection{Hypothesis Testing: Direct Effects}

As can be seen in Table 7 six out of seven hypotheses of the direct effects $(\mathrm{H} 1-\mathrm{H} 7)$ are supported: Performance Expectancy (H1), Effort Expectancy (H2), and Social Influence (H3) positively influenced Attitude towards Use (AtU) while Perceived Security Risks negatively influenced Attitude towards Use (H6). We did not find a significant effect of Perceived Trust influencing Attitude towards Use (H5), while Facilitating Conditions (H4) and Attitude towards Use (H7) have a direct positive effect on Behavioral Intention using cloud services.

Table 7. Path coefficients and hypothesis testing

\begin{tabular}{llllll}
\hline Hypothesis & Path & Coefficient & S.E. & p-value & Result \\
\hline H1 & PE $=>$ AtU & 0.453 & 0.068 & 0.000 & Supported \\
H2 & EE $=>$ AtU & 0.229 & 0.081 & 0.005 & Supported \\
H3 & SI => AtU & 0.553 & 0.102 & 0.000 & Supported \\
H4 & FC => INT & 0.989 & 0.065 & 0.000 & Supported \\
H5 & TR $=>$ AtU & 0.002 & 0.045 & 0.946 & Not supported \\
H6 & PSR $=>$ AtU & -0.267 & 0.048 & 0.000 & Supported \\
H7 & AtU $=>$ INT & 0.156 & 0.041 & 0.000 & Supported \\
\hline
\end{tabular}

\subsection{Structural Paths}

The Figure 2 show standardized path coefficients and fit indices. Except for Trust, we found significant path coefficients for six paths, whereby five out of seven paths exhibited p-values less than 0.01 as can be seen from Figure 2. 


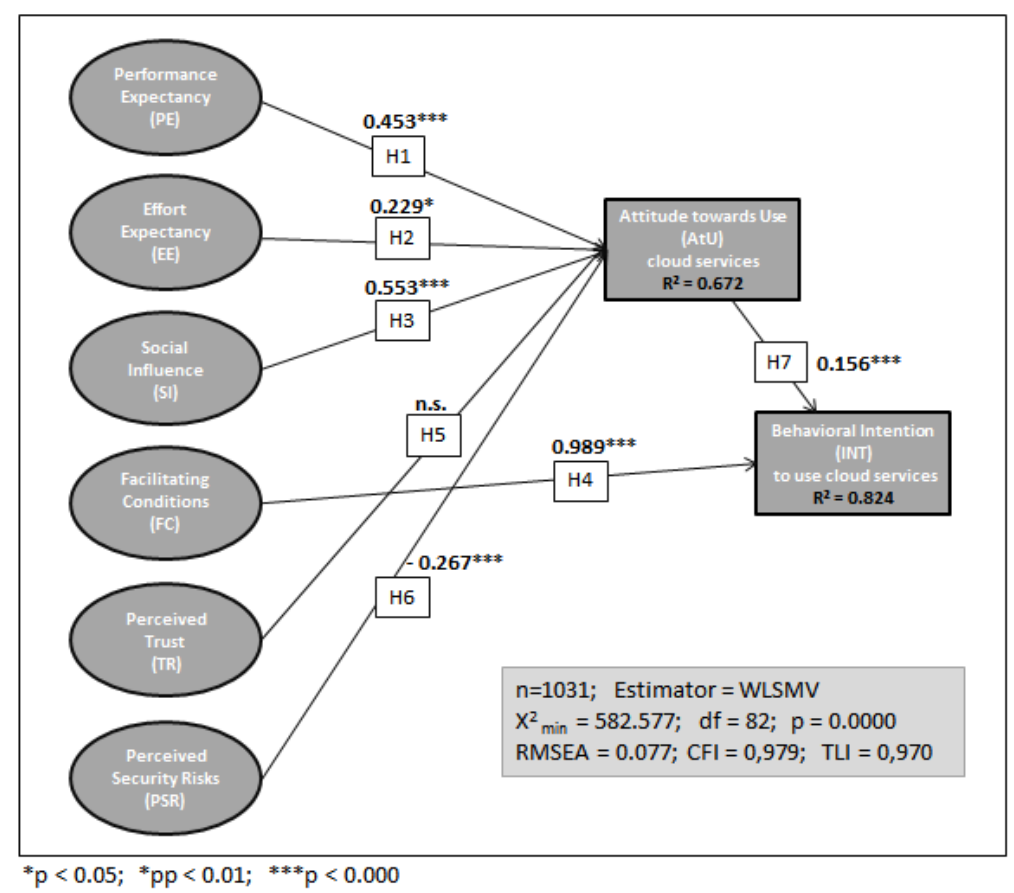

Figure 2. SEM analysis and hypothesis testing

The explanatory power of the research model is also checked. The proportion of explained variance of constructs is substantial with a maximum of $67.2 \%$ for Attitude towards Use (AtU) and $82.4 \%$ for Behavioral Intention (INT).

\subsection{Analysis of Moderating Effects}

The main purpose of this study was to investigate moderating variables including gender, age, IT experience and usage context. Moderating effects were analyzed applying multigroup analyses in AMOS in version 22. Each moderating variable was split into two groups and analyzed in comparison applying critical ratios approach (Byrne, 2010).

For the first group comparison moderating variable Gender was split into male $(\mathrm{N}=490)$ and female $(\mathrm{N}=514)$ respondents. Age was measured in years. The youngest respondent was 14 years old, the oldest 64 years of age. Average age of respondents is 37.21 years at MEAN (SD 12.2) and 36 at MEDIAN. For the second group comparison moderating variable age was split into a young age group (aged 14-36; $\mathrm{N}=514$ ) and older age group, with respondents aged 37-64 ( $\mathrm{N}=484)$. IT Experience was measured in categories between $0-1$ year and more than 10 years. Inexperienced respondents with up to two years of IT experience were merged into low experience group ( $\mathrm{N}=791)$ and experienced users with three years and more IT experience were clustered as high level of experience group $(\mathrm{N}=271)$. Respondents were further split based on the context using cloud services, where private cloud user $(\mathrm{N}=804)$ and business user $(\mathrm{N}=222)$ were selected for a group comparison in Usage Context.

Effects of all four moderating variables are documented in Table 8. Estimates are unstandardized coefficients. Z-scores indicate significance of difference between path coefficients. $\left({ }^{*}, * *\right.$ and $* * *$ indicate significance at $\mathrm{p}<0.1,0.05$ and 0.01 , respectively). 
Table 8. Effects of moderating variables

\begin{tabular}{|c|c|c|c|c|}
\hline Gender & & $\begin{array}{l}\text { Male Estimate } \\
\mathrm{N}=490\end{array}$ & $\begin{array}{l}\text { Female Estimate } \\
\mathrm{N}=514\end{array}$ & z-score \\
\hline Social Influence (SI) & Attitude & $0.088 * *$ & 0.058 & -0.66 \\
\hline Performance Expectancy (PE) & Attitude & $0.274 * * *$ & $0.443 * * *$ & $2.782 * * *$ \\
\hline Effort Expectancy (EE) & Attitude & $0.501 * * *$ & $0.283 * * *$ & $-2.859 * * *$ \\
\hline Perceived Security Risks (PSR) & Attitude & $0.124 * * *$ & 0.124 & 0.003 \\
\hline Perceived Trust (TR) & Attitude & 0.036 & $0.109 * * *$ & $2.032 * *$ \\
\hline Facilitating Conditions (FC) & Intention & $0.39 * * *$ & $0.396^{* * *}$ & 0.053 \\
\hline Attitude towards Use (AtU) & Intention & $1.202 * * *$ & $0.993 * * *$ & -1.46 \\
\hline Age & & $\begin{array}{l}\text { Young Estimate } \\
\mathrm{N}=514\end{array}$ & $\begin{array}{l}\text { Old Estimate } \\
\mathrm{N}=484\end{array}$ & z-score \\
\hline Social Influence (SI) & Attitude & $0.187 * * *$ & -0.072 & -0.237 \\
\hline Performance Expectancy (PE) & Attitude & $0.283 * * *$ & $0.431 * * *$ & -1.227 \\
\hline Effort Expectancy (EE) & Attitude & $0.422 * * *$ & $0.309 * * *$ & -0.913 \\
\hline Perceived Security Risks (PSR) & Attitude & $0.104 * *$ & $0.127 * *$ & -1.226 \\
\hline Perceived Trust (TR) & Attitude & 0.048 & $0.109 * * *$ & $3.978 * * *$ \\
\hline Facilitating Conditions (FC) & Intention & 0.135 & $0.864 * * *$ & $2.504 * *$ \\
\hline Attitude towards Use (AtU) & Intention & $1.273 * * *$ & $0.754 * * *$ & $-2.727 * * *$ \\
\hline IT Experience & & $\begin{array}{l}\text { Experienced Estimate } \\
\mathrm{N}=791\end{array}$ & $\begin{array}{l}\text { Inexperienced Estimate } \\
\mathrm{N}=271\end{array}$ & z-score \\
\hline Social Influence (SI) & Attitude & 0.056 & 0.12 & 0.848 \\
\hline Performance Expectancy (PE) & Attitude & $0.351 * * *$ & $0.311 * * *$ & -0.514 \\
\hline Effort Expectancy (EE) & Attitude & $0.313 * * *$ & $0.521 * * *$ & $2.152 * *$ \\
\hline Perceived Security Risks (PSR) & Attitude & $0.129 * * *$ & 0.133 & 0.055 \\
\hline Perceived Trust (TR) & Attitude & $0.104 * * *$ & -0.042 & $-2.721 * * *$ \\
\hline Facilitating Conditions (FC) & Intention & $0.618 * * *$ & $0.404 * * *$ & -1.503 \\
\hline Attitude towards Use (AtU) & Intention & $1.037 * * *$ & $0.814^{* * *}$ & -1.439 \\
\hline Usage Context & & $\begin{array}{l}\text { Private User Estimate } \\
\mathrm{N}=804\end{array}$ & $\begin{array}{l}\text { Business User Estimate } \\
\mathrm{N}=222\end{array}$ & z-score \\
\hline Social Influence (SI) & Attitude & $0.069 * *$ & 0.059 & -0.19 \\
\hline Performance Expectancy (PE) & Attitude & $0.315 * * *$ & $0.499 * * *$ & $2.275^{* *}$ \\
\hline Effort Expectancy (EE) & Attitude & $0.357 * * *$ & $0.421 * * *$ & 0.656 \\
\hline Perceived Security Risks (PSR) & Attitude & $0.111^{* * *}$ & $0.148 * *$ & 0.597 \\
\hline Perceived Trust (TR) & Attitude & $0.101 * * *$ & 0.035 & -1.579 \\
\hline Facilitating Conditions (FC) & Intention & $0.417 * * *$ & $0.498 * * *$ & 0.552 \\
\hline Attitude towards Use (AtU) & Intention & $1.065^{* * *}$ & $1.012 * * *$ & -0.337 \\
\hline
\end{tabular}

\subsection{Findings: Direct Effects}

The results presented in Figure 5 show that Attitude towards Use (AtU) the cloud services is significantly influenced by Performance Expectancy (PE), Effort Expectancy (EE), Social Influence (SI), and Perceived Security Risks (PSR). Related to original UTAUT, these findings support hypotheses 1, 2, and 3. Additionally, the findings promote hypothesis 6, showing the importance of Perceived Security Risks (PSR) as a determinant to attitude to use cloud services. Perceived Trust (TR) did not show any significant influence on Attitude to Use cloud services, so hypothesis 5 has to be rejected. Facilitating Conditions (FC) and Attitude towards Use (AtU) both significantly influence Behavioral Intention (INT) to use cloud services-which lends support to hypotheses 4 and 7.

\subsection{Findings: Indirect Effects}

The main purpose of this study was to investigate moderator effects for cloud usage. Herby, Gender, Age, IT Experience, and Usage Context were included as moderating variables. Table 8 presents the results whereby $z$-scores indicate the significance of difference between path coefficients.

The results presented start with Gender as a moderating variable. Hereby, Performance Expectancy has a significant impact on Attitude to Use among both men and women, whereby the effect is significantly stronger among women. Our initial hypothesis predicted a stronger effect amongst men, so hypothesis H8a must be rejected. A further result is a difference in the effect of Effort Expectancy on Attitude towards Use for both men and women, whereby the effect is stronger among men. Hypothesis H8b predicted a stronger effect amongst women, so it has to be rejected. Perceived Trust has a significant effect on Attitude to Use among women, 
indicating that cloud services are considered as more trustworthy among women which lends support to hypothesis H8d. The rest of the factors investigated show no significant $\mathrm{z}$-scores, indicating that there are no significant differences amongst men and women found for Perceived Security Risks, Social Influence, Facilitating Conditions and Attitude towards Use, which means a rejection of hypotheses H8c and H8e.

Age is the second moderating variable to be investigated. Hereby, Perceived Trust has a significant impact on Attitude towards Use among older respondents. This lends support to hypothesis H9e. Although not hypothesized, a further result is a difference in the effect of Facilitating Conditions on Behavorial Intention among older respondents as well as for Attitude towards Use on Behavioral Intention for both the young and old age group whereby the effect is stronger among young respondents. For the rest of the construct no significant difference between young and old respondents is observed, so hypotheses H9a, H9b, H9c, and H9d must be rejected.

IT Experience is the next moderating variable to be investigated. Hereby, Effort Expectancy has a significant impact on Attitude towards Use among both inexperienced and experienced IT user whereby the effect is stronger among inexperienced respondents. This leads support to hypothesis H10a. A further result is a significant effect of Perceived Trust on Attitude towards Use for experienced users which promotes hypothesis H10d. For the rest of the construct no significant difference between young and old respondents is observed, so hypotheses H10b, H10c, and H10e must be rejected.

Last moderator variable investigated is Usage Context by a split in private and business cloud usage. Although not hypothesized, construct Performance Expectancy shows a significant effect on Attitude towards Use for both private and business user whereby the effect among business user is stronger. For the rest of the construct no significant difference among private and business user can be observed.

\section{Discussion \& Implications}

This study contributes to research in several ways. First, the study takes a complete perspective on explaining acceptance of cloud based storage services through a contextualized version of the UTAUT model — adding attitude towards use, perceived trust and security risks to the original UTAUT model (Venkatesh et al., 2003). The current state of research shows that trust and security risks are important aspects to be considered in order to explain users' acceptance in the online environment (Lee et al., 2010). However, such efforts to combining both constructs into UTAUT are not tested empirically or validating only certain aspects of their casual relationships (Lee et al., 2010; Im et al., 2008; Shin, 2009).

Also, the inclusion of moderating variables contributes to a comprehensive and more nuanced understanding of consumers' acceptance of cloud services missing in prior research (Moryson \& Moeser, 2015). By including a broad selection of potential factors influencing acceptance of cloud services, a better understanding is offered to suppliers and managers introducing such services in a market (Nysveen \& Pedersen, 2014). This improved understanding is related both to the general antecedents and also to the understanding of the importance of the various moderating effects of gender, age, IT experience, and usage context.

\subsection{Direct Influences}

Except Perceived Trust, all constructs investigated in this empirical study, Performance Expectancy, Effort Expectancy, Social Influence, and Perceived Security Risk were demonstrated to significantly influence Attitude towards Use cloud services in Germany. Additionally, Attitude towards Use and Facilitating significantly directly influence Behavioral Intention to use cloud services in Germany.

Social Influence (SI) was significantly shown as the strongest driver of Attitude towards Use cloud services. This result was expected, having been identified as a significant predictor in IT-related technology acceptance literature (Nysveen \& Pedersen, 2014). Our study reconfirms this finding and underscores that other peoples' opinions strongly influence users thinking regarding the attitude of cloud services.

Further, the results show that Performance Expectancy (PE) is a highly significant antecedent of attitude to use cloud services. This result was expected as it has been identified as a vital intention driver in other UTAUT related studies. This finding provides evidence that increased Performance Expectancy on cloud services can lead to a more positive attitude to use cloud services. It underscores the functional level represented by an increasing productivity and efficiency in data processing is important for people to accept cloud computing services. A managerial implication of this result is that project teams designing cloud services should have a strong focus on innovating services that are perceived to be useful among the customers targeted (Nysveen \& Pedersen, 2014).

Effort Expectancy (EE) was shown to be another keen predictor of Attitude towards Use of cloud services. The 
results mean that not all respondents are savvy with the services as the factor appeared to be significant. Easy to use cloud service is an important topic for cloud users. It should remain as an obligation for cloud service to be easy to use and to communicate that in order to be attractive for users that are not considered tech-savvy (Moryson \& Moeser, 2015). Assuming that user-friendly services reduce the degree of service problems, this highlights the importance of involving consumers in the innovation process to make sure that the future services developed are easy to use (Nysveen \& Pedersen, 2014).

Perceived Security Risk was shown to significantly decrease Attitude towards Use cloud services. With that evidence provided, users who believe in using cloud services increase their sensitivity to these risks and are less likely to have a positive attitude towards the use of cloud services. The results from our study show that technology anxiety has a negative influence on customers' attitudes towards using cloud services. Although technology-based services are becoming more and more common, the results indicate that consumers' fear of security risks like data protection when using such services is a potential inhibitor for their attitude to use the service (Nysveen \& Pedersen, 2014).

Perceived Trust (TR) has no direct significant impact on Attitude to Use cloud services. Although a bit surprising, it seems that trust appears to rather influence behavioral intention directly and not channeled via attitude as in a previous study trust was shown as a significant predictor of Behavioral Intention (Moryson \& Moeser, 2015). Also, other studies have shown that trust is a critical factor to intention in the whole IT environment but not measured via attitude to use IT services (e.g. Lee et al., 2010).

Attitude towards Use (AtU) was shown to be a significant antecedent of Behavioral Intention to use cloud services. This finding was expected as it goes in line with current empirical findings of other research showing that general attitudinal measures of technology are highly significant antecedents of intention to use (Nysveen \& Pedersen 2014). The finding is also promising in order to better understand the moderating effects with respect to different user segments.

Facilitating Conditions (FC) was shown to be a significant determining contributor of Behavioral Intention. In the original UTAUT research model FC is a direct predictor for actual system usage and is not measured indirectly via users' intention. However, when linking FC to INT it is shown that FC is a strong driver of users' intention. This finding reconfirms a finding from a previous study (Moryson \& Moeser, 2015) and provides evidence that having the resources and knowledge required for as well as access to the needed technical support to transact online increases the users' intention and therefore should also support the actual use as measured in Venkatesh et al. (2003).

\subsection{Indirect Influences}

It is interesting to see that some of the traditional gender roles are outdated when it comes to new technology such as cloud services. These results have significant managerial importance because different strategies should be applied to stimulate adoption for women and for men (Nysveen \& Pedersen, 2014). In detail, although Performance Expectancy is a significant antecedent for Attitude to Use cloud services for both men and women, it is particularly important that the service is utility oriented and includes features perceived as useful when targeting women. We observed the opposite between both genders when it comes to the effect of Effort Expectance on Attitude to Use. Both effects between men and women are significant but the effect is surprisingly stronger amongst men. This reflects more sensitivity to user-friendly aspects amongst men, and is an important message to service developers targeting male segments of the population. We observed other significant differences between the genders when it comes to the effect of Perceived Trust. The effect amongst women is significant while the effect is not significant amongst men, indicating that stimulation of perceived trust is in general not a suitable strategy for increasing the adoption rate amongst men.

Related to the UTAUT core model there seems to be less need to divide consumers based on age, as age only moderates the effect of facilitating conditions and the extended factors perceived trust on attitude which itself moderates directly behavioral intention to use cloud services. The lack of support for the moderating influences of age within UTAUT core model is in line with the original empirical results from Venkatesh et al. (2003), who found only moderating effects of the influence as well of facilitating conditions on usage, and Venkatesh et al. (2012), who found no moderating influences of age (Nysveen \& Pedersen, 2014). The effect for facilitating conditions is significantly strong amongst older users, indicating facilitating conditions, like knowledge resources, are most important particularly amongst older users. This effect was expected but is an important message to service developers targeting age segments. Perceived Trust is a significant antecedent for Attitude to Use cloud services for older users and not significant amongst younger users. Hence it is particularly important that the services build trust in particular among older users. Although not hypothesized, Attitude on Behavioral 
Intention to use cloud services is significantly moderated by both young and old age groups whereby the effect is stronger amongst younger users.

With Effort Expectancy only one construct of the UTAUT core model is moderated by consumers' IT experience. The result is in line with the lack of empirical support for similar moderating influences shown by both Venkatesh et al. (2003) and Venkatesh et al. (2012). Effort Expectancy is significantly moderated by both experienced and inexperienced IT users whereby the effect is stronger amongst inexperienced users. Again, this effect was expected but is an important message to service developers targeting groups with various levels of IT experience and reflects more sensitivity to user-friendly aspects in particular amongst inexperienced users. Another moderating effect is observed with Perceived Trust on Attitude to Use, whereby the effect is only significant amongst experienced users. Hence it is important that the services build trust in particular amongst more experienced users, possibly with knowledge of or own experiences, in terms of abuse of data privacy protection aspects.

Although not hypothesized, we finally investigated moderating effects among cloud users for private or business purposes. Table 8 shows only one factor moderated by usage context. Performance Expectancy is a significant antecedent for Attitude to Use cloud services for both private and business users with a stronger effect among business users. It indicates that the usefulness in terms of an increased productivity is perceived stronger in business that in private life. Surprisingly is that constructs Perceived Trust and Perceived Security Risks are not moderated by usage context.

\section{Conclusion}

The main purpose of our research was to addresses the question whether there are moderator effects for cloud usage. Herby, gender, age, IT experience, and usage context were included as moderating variables. Further we embedded Attitude towards Use cloud services into the research model as additional variable to get a better and more nuanced understanding of the moderating effects. Hypotheses were setup for direct (structural paths) and indirect (moderating) effects. To answer these questions we developed and empirically validated a new research model by extending UTAUT with Perceived Trust and Perceived Security Risk as new factors plus integrated Attitude towards Use. Cloud based storage services in Germany were chosen to be the object of investigation because they significantly reflect the features of trust and perceived risks and have currently been investigated very little. Furthermore, we made good on the groundwork with the investigation of cloud services in a previous study (Moryson \& Moeser, 2015) and were interested to dig deeper into the research object in order to find a comprehensive research picture. In particular, we wanted to point out two main findings.

First, results of the measurement and structural model were used to test the direct effects of our proposed research model. The results show that extended UTAUT is a robust research model. In detail, Social Influence, Performance Expectancy Effort Expectancy, and Perceived Security Risks were shown to significantly impact Attitude towards Use cloud services. Attitude towards Use was also shown to significantly influence Behavioral Intention to use cloud services in Germany. Perceived Trust did not show significant impact on Attitude to Use, but was shown to significantly influence Behavioral Intention directly (Moryson \& Moeser, 2015). The combination of all constructs used accounted for $67.2 \%$ of the variances observed in users' attitude and $82.4 \%$ in users' intention to use cloud services. It indicates that extended UTAUT with attitude, trust and security risks included has strong predictive power.

Second, critical ratios approach (Byrne, 2010) was applied to investigate moderating effects. In particular gender and IT experience were shown to significantly moderate attitude and behavioral intention to use cloud services. In detail, gender moderates the effects for performance expectancy, effort expectancy and perceived trust. These results have significant managerial importance because different strategies should be applied to stimulate adoption for women and for men. Additionally, IT experience moderates the effects for effort expectancy and perceived trust. These findings reflect more sensitivity to user-friendly aspects in particular amongst inexperienced users, respectively, and underscore the meaning for building trust among experienced users.

\subsection{Implications for Theory and Practice}

The results of this research provide implications for cloud service suppliers and marketing. We want to point out two implications in particular.

The first implication is related to social influence. It is shown that the factor of social influence is the strongest driver of users' attitude to use cloud services. As this finding goes in line with previous research where social influence was the top driver for behavioral intention to use cloud services, this underscores even more the meaning of social power (Moryson \& Moeser, 2015). Again, others people's opinions regarding cloud computing 
services are highly relevant for the acceptance of cloud computing services in Germany (Moryson \& Moeser, 2015). Furthermore, although we found high correlation between trust and social influence, as well as the strong direct impact of social influence to behavioral intention (Moryson \& Moeser, 2015), we did not find a significant direct impact of trust to attitude towards use of cloud services.

The second implication is related to the inclusion of Attitude towards Use. It was shown that the integration of factor connected to Behavioral Intention was useful as important explanation power for users' intention and to better understand moderating effects. Furthermore, it deepens the understanding of their relationships of how gender, age, IT experience and usage context place value on all attitudinal constructs and finally direct the intention to use cloud services. When viewed from a practical perspective, our research implied that building a positive attitude was important to activate cloud computing services in Germany. In addition, the results of the moderating effects have significant managerial importance because different strategies should be applied to stimulate adoption for different target groups.

\subsection{Limitations \& Future Research}

Notwithstanding our study's usefulness for theory and practice, the research has some limitations. First, data is based on German respondents. Although cloud services are widely used globally, the results might differ from data results of other countries. Second, the data surveyed is cross sectional. While users' intent on using cloud services can be considered as an ongoing process, our measurement items were measured at a single point. Fourth, trust and perceived security risks were considered as one dimension, although they are accepted to be considered as multi-dimensions (Lee et al., 2010). Fifth, while users' intention is surely a strong predictor of actual system usage, our research model uses behavioral intention channeled by attitude towards use as the dependent constructs for cloud usage.

Consequently, a possible direction for future research could be the use of longitudinal data, the multi-dimensional character of trust and perceived security risks in order to get a better understanding of the mechanism on users' acceptance of cloud services.

In addition to this more qualitative studies could be conducted where cloud services can be discussed in more depth, and where issues related to adoption and rejection can be discussed and elaborated on a more deeply basis by users and non-users. In this context could be explored also other criteria for adoption than the antecedents applied in this study. This will provide the foundation for models explaining even a higher level of variance in attitude or behavioral intention to use cloud services in the future. Also, the increasing number of various cloud services that are or will be available in consumer markets in upcoming years will need a separate investigation by segments in order to get a better understanding and comparison of adoption criteria amongst different services and consumers.

\section{Acknowledgments}

This study was graciously supported by the German Association for Online Research ("Deutsche Gesellschaft für Online Forschung e.V. - DGOF") based on a sponsorship application ("DGOF-Fonds zur Förderung der Online-Forschung"). A special thanks goes to Micah Q. Jones for his English proof of the manuscript.

\section{References}

Ajzen, I. (1991). The theory of planned behavior. Organizational Behavior and Human Decision Processes, 50(2), 179-211. http://dx.doi.org/10.1016/0749-5978(91)90020-T

Ajzen, I. (2005). Attitudes, personality and behavio (2nd ed.). Milton Keynes. Open Univ. Pr.

Alston, M., Allan, J., Dietsch, E., Wilkinson, J., Shankar, J., Osburn, L., ... Grantley, J. (2006). Brutal neglect. Australian rural women's access to health services. Rural and Remote Health, 6(1), 475.

Awad, N. F., \& Ragowsky, A. (2014). Establishing Trust in Electronic Commerce Through Online Word of Mouth. An Examination Across Genders. Journal of Management Information Systems, 24(4).

Bergeron, F., Rivard, S., \& De Serre, L. (1990). Investigating the support role of the information center. MIS quarterly, 247-260. http://dx.doi.org/10.2307/248887

Boslau, M., \& Lietke, B. (2006). RFID aus Konsumentensicht. Umfrageergebnisse und Implikationen. GHS.

Brown, T. (2006). Confirmatory factor analysis for applied research. New York: Guilford Press.

Byrne, B. M. (2010). Structural equation modeling using AMOS. Basic concepts, applications, and programming. New York: Routledge.

Cody-Allen, E., \& Kishore, R. (2006). An extension of the UTAUT model with e-quality, trust, and satisfaction 
constructs. In S. Conrad, K. Kate, \& R. Terry (Eds.), The 2006 ACM SIGMIS CPR conference (p. 82). Claremont, California, USA. http://dx.doi.org/10.1145/1125170.1125196

Crespo, Á. H., del Bosque, I., Rodríguez., de los S. S., \& García, M. M. (2009). The influence of perceived risk on Internet shopping behavior. A multidimensional perspective. Journal of Risk Research, 12(2), 259-277. http://dx.doi.org/10.1080/13669870802497744

Davis, F. D., Bagozzi, R. P., \& Warshaw, P. R. (1989). User Acceptance of Computer Technology. A Comparison of Two Theoretical Models. Management Science, 35(8), 982-1003. http://dx.doi.org/1287/mnsc.35.8.982

Esteva-Armida, E., \& Rubio-Sanchez, A. (2014). The Influence of Trust in the UTAUT Model. In H. R. Nemati (Ed.), Analyzing Security, Trust, and Crime in the Digital World (pp. 162-186). IGI Global. http://dx.doi.org/10.4018/978-1-4666-4856-2.ch008

Fishbein, M., \& Ajzen, I. (2010). Predicting and changing behavior. The reasoned action approach. New York: Psychology Press.

Garbarino, E., \& Strahilevitz, M. A. (2004). Gender Differences in the Perceived Risk of Buying Online and the Effects of Receiving a Site Recommendation. Journal of Business Research, 57, 768. http://dx.doi.org/10.1016/S0148-2963(02)00363-6

Gefen, D. (2000). E-commerce. The role of familiarity and trust. Omega, 28(6), 725-737. http://dx.doi.org/10.1016/S0305-0483(00)00021-9

Gefen, D., Karahanna, E., \& Straub, D. W. (2003). Inexperience and experience with online stores. The importance of tam and trust. IEEE Trans. Eng. Manage, 50(3), 307-321. http://dx.doi.org/10.1109/TEM.2003.817277

Guo, Y., \& Barnes, S. (2007). Why people buy virtual items in virtual worlds with real money. SIGMIS Database 38(4), 69. http://dx.doi.org/10.1145/1314234.1314247

Hair, J. F. (2014a). A primer on partial least squares structural equations modeling (PLS-SEM). Los Angeles: SAGE.

Hair, J. F. (2014b). Multivariate data analysis (7th ed.). Pearson new internat. ed. Pearson custom library.

Hall, D. T., \& Mansfield, R. (1975). Relationships of age and seniority with career variables of engineers and scientists. Journal of Applied Psychology, 60(2), 201-210. http://dx.doi.org/10.1037/h0076549

Hoyer, W. J., \& Plude, D. J. (1980). Attentional and perceptual processes in the study of cognitive aging. Psychology and Aging, ll(1), 4-10. http://dx.doi.org/10.1037/0882-7974.1.1.4

Hu, L., \& Bentler, P. M. (1999). Cutoff criteria for fit indexes in covariance structure analysis. Conventional criteria versus new alternatives. Structural Equation Modeling. A Multidisciplinary Journal, 6(1), 1-55. http://dx.doi.org/10.1080/10705519909540118

Im, I., Kim, Y., \& Han, H. (2008). The effects of perceived risk and technology type on users' acceptance of technologies. Information \& Management, 45(1), 1-9. http://dx.doi.org/10.1016/j.im.2007.03.005

Lee, J., Sook, W. K., \& Song, C. H. (2010). The Effects of Trust and Perceived Risk on Users' Acceptance of ICT Services. SSRN Journal.

Lee, M. (2009). Factors influencing the adoption of internet banking. An integration of TAM and TPB with perceived risk and perceived benefit. Electronic Commerce Research and Applications, 8(3), S, 130-141. http://dx.doi.org/10.1016/j.elerap.2008.11.006

Marinescu, D. C. (2013). Storage Systems. Cloud Computing, 241-271. Amsterdam: Elsevier. http://dx.doi.org/10.1016/b978-0-12-404627-6.00008-7

Minton, H. L., \& Schneider, F. W. (1985). Differential psychology. Waveland PressInc.

Moeser, G., Moryson, H., \& Schwenk, G. (2013). Determinants of Online Social Business Network Usage Behavior-Applying the Technology Acceptance Model and Its Extensions. PSYCH, 4(4), S, 433-437. http://dx.doi.org/10.4236/psych.2013.44061

Moore, G. C., \& Benbasat, I. (1991). Development of an instrument to measure the perceptions of adopting an information technology innovation. Information systems research, 2(3), 192-222.

Moryson, H., \& Moeser, G. (2015). Lucky Users on Cloud Nine? Determinants of Cloud Computing Usage Behavior in Germany. Journal of Emerging Trends in Computing and Information Sciences, 6(7), 375-385. 
Müller-Seitz, G., Dautzenberg, K., Creusen, U., \& Stromereder, C. (2009). Customer acceptance of RFID technology. Evidence from the German electronic retail sector. Journal of Retailing and Consumer Services, 16(1), 31-39. http://dx.doi.org/10.1016/j.jretconser.2008.08.002

Nicolaou, Andreas, I., \& McKnight, D. H. (2006). Perceived Information Quality in Data Exchanges. Effects on Risk, Trust, and Intention to Use. Information Systems Research, 17(4), 332-351. http://dx.doi.org/10.1287/isre.1060.0103

Nysveen, H., \& Pedersen, P. E. (2014). Influences of co-creation on brand experience. The role of brand engagement. International Journal of Market Research, 56(6), 807-832. http://dx.doi.org/10.2501/IJMR-2014-016

Paul, A. P. (2003). Consumer Acceptance of Electronic Commerce. Integrating Trust and Risk with the Technology Acceptance Model. Int. J. Electron. Commerce, 7(3), 101-134.

Pavlou, P. A., \& Gefen, D. (2004). Building Effective Online Marketplaces with Institution-Based Trust. Information Systems Research, 15(1), 37-59. http://dx.doi.org/10.1287/isre.1040.0015

Porter, L. (1963). Job attitudes in management. Perceived importance of needs as a function of job level. Journal of Applied Psychology, 47(2), 141-148. http://dx.doi.org/10.1037/h0041677

Pramatari, K., \& Theotokis, A. (2009). Consumer acceptance of RFID-enabled services. a model of multiple attitudes, perceived system characteristics and individual traits. European Journal of Information Systems, 18(6), 541-552. http://dx.doi.org/10.1057/ejis.2009.40

Rhodes, S. R. (1983). Age-related differences in work attitude and behavior. A review and conceptual analysis. Psychological Bulletin, 93(2), 328-367. http://dx.doi.org/10.1037/0033-2909.93.2.328

Ronan, R., \& Kim, D. Y. (2006). Gender differences in explicit and implicit risk attitudes. A socially facilitated $\begin{array}{lllll}\text { phenomenon. British Journal of Social Psychology, } & \text { 45, }\end{array}$ http://dx.doi.org/10.1348/014466605X66420

Shin, D. H. (2009). Towards an understanding of the consumer acceptance of mobile wallet. Computers in Human Behavior, 25(6), S, 1343-1354. http://dx.doi.org/10.1016/j.chb.2009.06.001

Venkatesh, V., Morris, M. G., Davis, G. B., \& Davis, F. D. (2003). User Acceptance of Information Technology. Toward a Unified View. MIS Quarterly, 27(3), 425-478.

Venkatesh, V., Thong, J. Y., \& Xu, X. (2012). Consumer acceptance and use of information technology. extending the unified theory of acceptance and use of technology. MIS Quarterly, 36(1), 157-178.

Williams, M. D., Rana, N., Dwivedi, Y. K., \& Lal, B. (2011). Is UTAUT really used or just cited for the sake of it? A systematic review of citations of UTAUT's originating article. Conference. 19th European Conference on Information Systems, ECIS 2011, Helsinki. In C. A. Anderson, D. A. Gentile, \& K. E. Buckley (Eds.), Violent video game effects on children and adolescents: Theory, research and public policy. http://dx.doi.org/10.1093/acprof:oso/9780195309836.001.0001

\section{Copyrights}

Copyright for this article is retained by the author(s), with first publication rights granted to the journal.

This is an open-access article distributed under the terms and conditions of the Creative Commons Attribution license (http://creativecommons.org/licenses/by/3.0/). 